\title{
Henoch-Schönlein purpura associated with a neuroblastoma: Report of one case and a review of the literature
}

\author{
Qiaoli Dong ${ }^{1,2}$, Shanshan Cao ${ }^{1,3}$, Hongwen Zhang ${ }^{1, *}$, Hui Geng ${ }^{1}$ \\ ${ }^{1}$ Department of Pediatrics, Peking University First Hospital, Beijing, China; \\ ${ }^{2}$ Department of Pediatrics, Affiliated Hospital of Hebei University, Baoding, China; \\ ${ }^{3}$ Health Center, Beijing Entry-exit Inspection and Quarantine Bureau, Beijing, China.
}

\begin{abstract}
Summary Malignancies such as solid tumors and hematologic malignancies can often induce or be associated with Henoch-Schönlein purpura (HSP) in older males but not in children. Described here is the case of a 5-year-old boy who clinically presented with HSP. An imaging study of the abdomen revealed a right retroperitoneal neoplasm that histopathology postoperatively confirmed to be a neuroblastoma. Malignancies are sometimes associated with HSP mostly in older males, though children are affected, albeit rarely. Thus, all patients with HSP must be carefully examined to identify or exclude an underlying disease.
\end{abstract}

Keywords: Henoch-Schönlein purpura (HSP), neuroblastoma, malignancy

\section{Introduction}

Henoch-Schönlein purpura (HSP) is the most common vasculitic disease affecting children. HSP is a multisystem immunoglobulin A-mediated vasculitis with a self-limited course that affects the skin, joints, gastrointestinal tract, and kidneys $(1,2)$. HSP has many causes, including infections, drugs, foods, and malignant tumors. Many malignancies, such as solid tumors and hematologic malignancies, are reported to induce or be associated with HSP. Such tumors include carcinoma of the lung, bronchus, esophagus, stomach, intestine, breast, kidney, prostate, and thyroid (3-12) while hematologic malignancies include non-Hodgkin lymphoma, Hodgkin disease, multiple myeloma, myeloproliferative disease, and myelodysplastic syndrome $(10,11,13-17)$.

However, patients with HSP associated with a malignancy are mostly older males with a mean age of 60 years $(7,8,10,11)$. Neuroblastomas are the most common extracranial solid tumors in children, but there are no reports of children with HSP associated with a neuroblastoma as has been reported here.

\footnotetext{
*Address correspondence to:

Dr. Hongwen Zhang, Department of Pediatrics, Peking University First Hospital, No.1, Xi An Men Da Jie, Beijing 100034, P. R. China.

E-mail: zhanghongwen@yeah.net
}

\section{Case report}

A 5-year-old boy with a weight of $19.5 \mathrm{~kg}(75$ percentile), height of $110.0 \mathrm{~cm}$ (50 percentile), and blood pressure of $100 / 75 \mathrm{mmHg}$ presented with numerous purpuras, bilateral knee joint pain, and abdominal pain without bloody diarrhea at almost the same time. The boy had no upper respiratory tract infections or other precipitating factors prior to the onset of those symptoms. A physical examination on admission found numerous flat or palpable purpuras that were typical of HSP in both lower extremities. There were no signs or abnormal findings upon physical examination of the abdomen. No lymphadenopathy and hepatosplenomegaly was evident. The boy was diagnosed with HSP.

Laboratory results such as urine output, renal function, prothrombin time, complements $\mathrm{C} 3$ and $\mathrm{C} 4$, anti-double stranded DNA antibodies, antinuclear antibodies, and anti-smooth muscle antibodies, $\mathrm{C}$-reaction protein, and antistreptolysin $\mathrm{O}$ were all normal. The boy was treated with vitamin $\mathrm{C}$, calcium gluconate, cimetidine, and dipyramidole. Joint pain and abdominal pain improved but purpuras did not change. A routine abdomen ultrasound two weeks after the diagnosis of HSP revealed a right adrenal-occupying lesion $(4 \mathrm{~cm} \times 6 \mathrm{~cm})$ and magnetic resonance imaging suggested a neoplasm. Further laboratory tests revealed higher levels of vanillylmandelic acid (VMA) and 
homovanillic acid (HVA) in the urine. Histopathology confirmed the neoplasm to be an adrenal neuroblastoma (stage II, American Children's Oncology Group staging system, CCSG). HSP completely resolved soon after surgery, and continued chemotherapy was given using the OPEC schedule (vincristine [O], cisplatin [P], etoposide [E], and cyclophosphamide [C]). HSP did not recur during a follow-up of 12 months.

\section{Discussion}

The patient experienced purpura and joint and abdominal pain without kidney involvement, fulfilling the diagnostic criteria for HSP (18). Abdominal ultrasound and magnetic resonance imaging revealed a right retroperitoneal neoplasm that histopathology postoperatively confirmed to be a neuroblastoma. HSP was associated with a neuroblastoma in this 5 -yearold boy. Moreover, neuroblastoma was an incidental finding diagnosed by the routine abdomen ultrasound; the patient had no abdominal signs or abnormal physical findings on admission.

Malignancies are known to cause vasculitis like HSP. In 2006, Zurada et al. (11) reviewed literature on adult malignancy-associated HSP from around the world, and they found a total of 31 cases. Patients were overwhelmingly male (94\%) with a mean age of 60 years and presented predominantly with solid tumors (61\%) and secondly with hematologic malignancies $(39 \%)$. The most frequent tumors were lung cancer $(n$ $=8)$, multiple myeloma $(n=5)$, prostate cancer $(n=5)$, and non-Hodgkin lymphoma $(n=3)$. The majority of patients $(55 \%)$ developed HSP within 1 month of cancer diagnosis or detection of metastases. Their findings were similar to those in a report by Pertuiset et al. (8). In 2009, Mitsui et al. (10) reported 23 cases of HSP in patients with underlying malignant tumors. HSP was thought to be closely associated with a tumor in nine patients, and seven of the nine exhibited new metastatic lesions or died due to underlying cancer within 1-32 months. Based on these reports, HSP associated with a malignancy is characterized by: $i$ ) patients who are mainly older males (over 40-60 years: over $85 \%$ ); ii) development within 1-3 months of diagnosis or metastasis of a neoplasm; iii) causes are mostly solid tumors (over 60\%), and especially carcinoma of the lung, followed by hematologic malignancies (about $40 \%$ ); and $i v$ ) development in the absence of a precipitating factor. This suggests that adults, and especially older men who present with unexplained HSP, should be evaluated for an occult neoplasm $(5,6)$, while patients with a known history of malignancy who present with HSP should be evaluated for metastatic disease (11). A skin biopsy is an important way to determine the underlying pathology in adult HSP (17). Malignancies induce or are associated with HSP mostly in older males, but children can also be affected, albeit rarely. Funato et al. (19) reported acute lymphoblastic leukemia mimicking HSP in a 3-year-old boy.

Neuroblastomas are the most common extracranial solid tumors in children, accounting for about $8 \%-10 \%$ of all pediatric tumors $(20,21)$. That said, there are no reports of HSP associated with a neuroblastoma or other malignancy in children. The current case is the world's first case of HSP associated with a neuroblastoma.

Tumors are known to be one of the causes of vasculitis $(8,10,22)$. Vasculitis is reported to occur during the course of malignancies in $2.3 \%-8 \%$ of patients (23). The incidence of vasculitis in cancer is estimated to be 1 in 1,800 for hemopathies and 1 in 80,800 for solid tumors (24). The relationship between vasculitis and malignancy remains unclear: e.g. fortuitous association, paraneoplastic syndrome, or neoplasms induced by immunosuppressive drugs prescribed to treat vasculitis, and so on (25). HSP is an allergic vasculitis disease caused by an immunologic mechanism (26-29). Neoplasm antigens such as paraneoplastic antibodies or abnormally produced IgA lead to the formation of immune complexes that induce the lesions of HSP (10).

The development of HSP and a neuroblastoma at the same time in the current patient is curious. Maybe both diseases developed independently or maybe HSP was a paraneoplastic syndrome of the neuroblastoma. However, neuroblastomas are known to induce other forms of vasculitis such as Kawasaki disease (30). In the current patient, HSP was likely to be induced by the neuroblastoma. The first reason for this conjecture is because the neuroblastoma appeared to develop prior to HSP given to the size of the neuroblastoma and the course of HSP. Second, there were no precipitating factors before the onset of HSP and no relapse during 12 months of follow-up. However, genetic studies of the neuroblastoma, e.g. studies of the $N-M y c$ gene and paraneoplastic antibodies, were not performed, and neither was a skin biopsy.

In conclusion, many malignancies may cause HSP, but in older males HSP is mostly caused by solid tumors. Reported here is the first case of HSP associated with a neuroblastoma in a 5-year-old boy. Epidemiological studies are needed to determine the association between HSP and malignancy in children.

\section{References}

1. Gedalia A. Henoch-Schonlein purpura. Curr Rheumatol Rep. 2004; 6:195-202.

2. Reamy BV, Williams PM, Lindsay TJ. Henoch-Schönlein purpura. Am Fam Physician. 2009; 80:697-704.

3. Hughes RA, Bottomley DM, Keat AC, Drury A. Henoch-Schonlein purpura occurring in association with carcinoma of the breast. Eur J Med. 1993; 2:310-312.

4. Maestri A, Malacarne P, Santini A. Henoch-Schönlein syndrome associated with breast cancer. A case report. Angiology. 1995; 46:625-627. 
5. Weiler-Bisig D, Ettlin G, Brink T, Arnold W, Glatz-Krieger K, Fischer A. Henoch-schönlein purpura associated with esophagus carcinoma and adenocarcinoma of the lung. Clin Nephrol. 2005; 63:302-304.

6. Frigui M, Kechaou M, Ben Hmida M, Kamoun K, Khanfir A, Frikha M, Hachicha J, Bahloul Z. Adult Schönlein-Henoch purpura associated with epidermoid carcinoma of the lung. Nephrol Ther. 2009; 5:201-204.

7. Flynn AN, du Prey B, Al Ardati H, Raman M, Lemaire J. Adult-onset malignancy-associated Henoch-Schönlein purpura. Scand J Rheumatol. 2011; 40:325-326.

8 Pertuiset E, Liote F, Launay-Russ E, Kemiche F, CerfPayrastre I, Chesneau AM. Adult Henoch-Schönlein purpura associated with malignancy. Semin Arthritis Rheum. 2000; 29:360-367.

9 Negri M, Peruzy AD. On a case of Schöenlein-Henoch syndrome in a subject with thyroid adenocarcinoma. Rass Fisiopatol Clin Ter. 1961; 33:331-337.

10. Mitsui H, Shibagaki N, Kawamura T, Matsue H, Shimada S. A clinical study of Henoch-Schönlein Purpura associated with malignancy. J Eur Acad Dermatol Venereol. 2009; 23:394-401.

11. Zurada JM, Ward KM, Grossman ME. HenochSchönlein purpura associated with malignancy in adults. J Am Acad Dermatol. 2006; 55(Suppl 5):S65-70.

12. Blanco R, González-Gay MA, Ibáñez D, Alba C, Pérez de Llano LA. Henoch-Schönlein purpura as a clinical presentation of small cell lung cancer. Clin Exp Rheumatol. 1997; 15:545-547.

13. Blanco P, Denisi R, Rispal P, Deminière C, Pellegrin JL, Leng B, Aparicio M. Henoch-Schönlein purpura associated with segmental and focal proliferative glomerulonephritis in a patient with Hodgkin's disease. Nephrol Dial Transplant. 1999; 14:179-180.

14. Conte G, Conte FJ, Ojeda JM, Araos D, Poniachik J, Murray G, Flores C. Severe Henoch-Schönlein purpura in a patient with multiple myeloma. Rev Med Chil. 2000; 128:1255-1260.

15. Saurina A, Botey A, Solé M, Vera M, Pou M, Torras A, Darnell A. Henoch-Schönlein purpura nephritis associated with coagulase-negative staphylococci sepsis in a patient with myeloma. Nephrol Dial Transplant. 2001; 16:2441-2442.

16. Fox MC, Carter S, Khouri IF, Giralt SA, Prieto VG, Nash JW, Hymes SR. Adult Henoch-schönlein purpura in a patient with myelodysplastic syndrome and a history of follicular lymphoma. Cutis. 2008; 81:131-137.

17. Tabata R, Tabata C, Namiuchi S, Terada M, Yasumizu R,
Okamoto T, Nagai T. Adult T-cell lymphoma mimicking Henoch-Schönlein purpura. Mod Rheumatol. 2007; 17:57-62.

18. Mills JA, Michel BA, Bloch DA, et al. The American College of Rheumatology 1990 criteria for the classification of Henoch-Schönlein purpura. Arthritis Rheum. 1990; 33:1114-1121.

19. Funato M, Kaneko H, Kubota K, Ozeki M, Kanda K, Orii K, Kato Z, Fukao T, Kondo N. Pediatric acute lymphoblastic leukemia mimicking Henoch-Schönlein purpura. Pediatr Int. 2011; 53:766-768.

20. Malmstrom-Groth A. Cerebellar encephalopathy and neuroblastoma. Eur Neurol. 1972; 7:95-100.

21. Aydin GB, Kutluk MT, Buyukpamukcu M, Akyuz C, Yalcin B, Varan A. Neurological complications of neuroblastic tumors: Experience of a single center. Childs Nerv Syst. 2010; 26:359-365.

22. Watts RA, Lane S, Scott DG. What is known about the epidemiology of the vasculitides? Best Pract Res Clin Rheumatol. 2005; 19:191-207.

23. Blanco R, Martinez-Taboada VM, Rodriguez-Valverde V, García-Fuentes M. Cutaneous vasculitis in children and adults. Associated diseases and etiologic factors in 303 patients. Medicine (Baltimore). 1998; 77:403-418.

24. Greer JM, Longley S, Edwards NL, Elfenbein GJ, Panush RS. Vasculitis associated with malignancy. Experience with 13 patients and literature review. Medicine (Baltimore). 1988; 67:220-230.

25. Fain O, Hamidou M, Cacoub $\mathrm{P}$, et al. Vasculitides associated with malignancies: Analysis of sixty patients. Arthritis Rheum. 2007; 57:1473-1480.

26. Eleftheriou D, Dillon MJ, Brogan PA. Advances in childhood vasculitis. Curr Opin Rheumatol. 2009; 21:411-418.

27. Tizard EJ, Hamilton-Ayres MJ. Henoch Schönlein purpura. Arch Dis Child Educ Pract Ed. 2008; 93:1-8.

28. Roberts PF, Waller TA, Brinker TM, Riffe IZ, Sayre JW, Bratton RL. Henoch-Schönlein purpura: A review article. South Med J. 2007; 100:821-824.

29. Tullus K, Marks SD. Vasculitis in children and adolescents: Clinical presentation, etiopathogenesis, and treatment. Paediatr Drugs. 2009; 11:375-380.

30. Ohta S, Narita T, Kato H,Taga T, Takeuchi Y. A patient with Kawasaki disease who developed acute urinary retention due to pelvic neuroblastoma. Eur J Pediatr. 2002; 161:631.

(Received August 26, 2012; Revised October 21, 2012; Accepted October 27, 2012) 